\title{
Measurement of Polynuclear Aromatic Hydrocarbon Concentrations in the Plume of Kuwait Oil Well Fires
}

\author{
K. B. Olsen \\ C. W. Wright \\ C. Veverka \\ J. C. Ball ${ }^{(a)}$ \\ R. Stevens ${ }^{(b)}$
}

March 1995

Prepared for

the U.S. Department of Energy

under Contract DE-AC06-76RLO 1830

Pacific Northwest Laboratory

Richland, Washington 99352

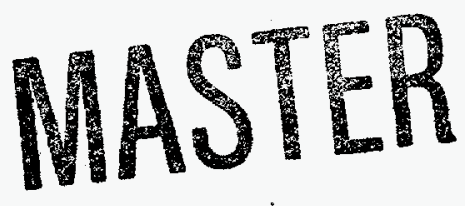

(a) Scientific Research Laboratory, Ford Motor Company.

(b)U. S. Environmental Protection Agency, Atmospheric Research and Exposure Assessment Laboratory. 



\section{DISCLAIMER}

This report was prepared as an account of work sponsored by an agency of the United States Government. Neither the United States Government nor any agency thereof, nor any of their employees, make any warranty, express or implied, or assumes any legal liability or responsibility for the accuracy, completeness, or usefulness of any information, apparatus, product, or process disclosed, or represents that its use would not infringe privately owned rights. Reference herein to any specific commercial product, process, or service by trade name, trademark, manufacturer, or otherwise does not necessarily constitute or imply its endorsement, recommendation, or favoring by the United States Government or any agency thereof. The views and opinions of authors expressed herein do not necessarily state or reflect those of the United States Government or any agency thereof. 


\section{DISCLAIMER}

Portions of this document may be illegible in electronic image products. Images are produced from the best available original document. 


\section{Summary}

With the cooperation of the U.S. Environmental Protection Agency (EPA), the Ford Motor Company, through a Cooperative Research and Development Agreement (CRADA) with the Motor Vehicle Manufactures Association and the U.S. Department of Energy (DOE), initiated a collaborative research effort to collect and characterize filter and Tenax trap samples for polynuclear aromatic hydrocarbon (PAH) compounds. Samples were collected in July and August 1991 in Kuwait and around the Persian Gulf region following the Persian Gulf War. Samples were collected using helicopter-mounted or aircraft-mounted sampling platforms. Near-field helicopter sampling was conducted by the EPA in the immediate vicinity of the Kuwait oil well fires to a maximum of $50 \mathrm{~km}$ downwind. Far-field sampling, using Pacific Northwest Laboratory's (PNL's) Gulfstream-1 aircraft, was conducted from 112 to $232 \mathrm{~km}$ downwind of the Kuwait oil well fires. Extraction and gas chromatography/mass spectroscopy (GC/MS) analysis of the near-field samples was conducted by the Ford Motor Company. Extraction and GC and GC/MS analysis of the far-field samples was conducted by PNL. The results of the sample analysis failed to identify PAH compounds above the detection limit of the analytical method. These results concur with those found by other independent researchers who conducted similar research in that region. This report presents the collection, analyses, and results of these samples. 


\section{List of Terms}

EPA U.S. Environmental Protection Agency

FID flame ionization detector

FMC Ford Motor Company

GC gas chromatography

GC/MS gas chromatography/mass spectrometer

NIST National Institute of Standards and Technology

PAH polynuclear aromatic hydrocarbon

PNL Pacific Northwest Laboratory

SRM Standard Reference Material

VAPS Versatile Air Pollution Sampler 


\section{Contents}

Summary $\ldots \ldots \ldots \ldots \ldots \ldots \ldots \ldots \ldots \ldots \ldots \ldots \ldots \ldots \ldots \ldots \ldots \ldots$

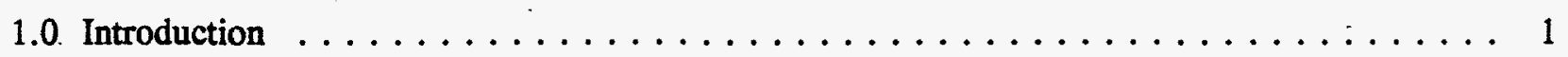

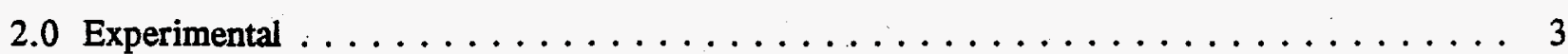

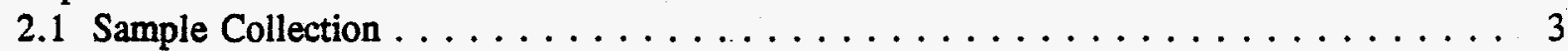

2.2 Sample Analysis . . . . . . . . . . . . . . . . . . . 9

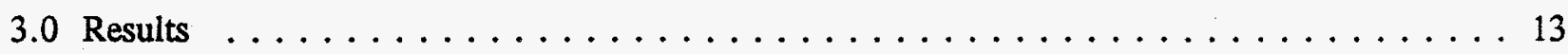

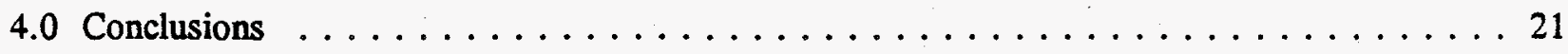

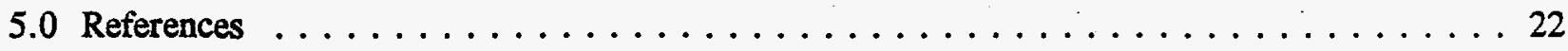

\section{Figures}

1 Map of Kuwait Showing Locations of Major Oil Fields and Numbers of Well Fires, March 1991

2 Schematic Diagram of the Helicopter Sampling Configuration and the VAPS Sampler

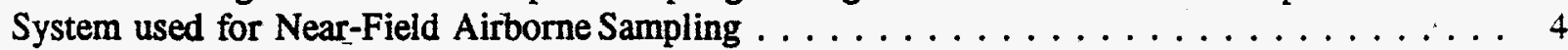

3 Locations of Far-Field Sampling (112 to $232 \mathrm{~km}$ downwind of Kuwait) Using PNL's Gulfstream-1 Aircraft. Bold lines indicate PAH sampling flight paths.

4 Diagram of a Specially Designed Filter Pack for PAH Sampling Developed to be Easily Installed and Removed from the Filter-Collection System

5 Chromatogram $-1.0 \mu \mathrm{L}$ Injection of $1.0 \mathrm{ng} / \mu \mathrm{L}$ of Napthalene, Acenapthene, Acenapthylene, Fluorene, Phenanthrene, Anthracene, Fluoranthene, Pyrene, Benzo[a]anthracene, Chrysene, Benzo[b]fluoranthene, Benzo[k]fluoranthene, Benzo[a]pyrene, Indeno[1,2,3-cd]pyrene, Dibenzo[ah]anthracene, and Benzo[ghi]perylene

6 Chromatogram - $1.0 \mu \mathrm{L}$ of a Methylene Chloride Extract of a Filter that Sampled

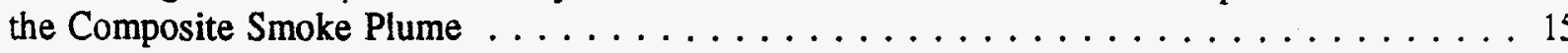

7 Chromatogram $-1.0 \mu \mathrm{L}$ of a Methylene Chloride Extract of a Blank Filter . . . . . . . 16 


\section{Tables}

1 Sample and Sampling Parameters for EPA Helicopter Near-Field Sampling . . . . . . . 5 5

2 Sample and Sampling Parameter for G-1 Aircraft Far-Field Study . . . . . . . . . . 7

3 Polycyclic Aromatic Hydrocarbons Analyzed by Selected Ion Gas Chromatography/

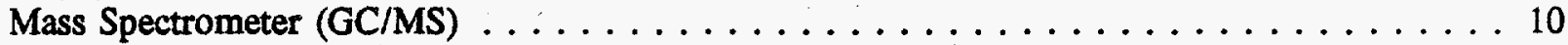

4 Filter Samples - Total ng Amounts Detected ${ }^{*} \ldots \ldots \ldots \ldots \ldots \ldots \ldots$

5 Tenax Traps - Total ng Amounts Detected $\ldots \ldots \ldots \ldots \ldots \ldots$

6 Urban Dust and Shale Oil - Total ng Amounts Detected . . . . . . . . . . . . 20 


\subsection{Introduction}

Following their retreat from Kuwait during February and March of 1991, the Iraqi Army set fire to over 500 oil wells dispersed throughout the Kuwait oil fields (Figure 1). During the period of sampling from July to August 1991, it was estimated that between $3.29 \times 10^{6}$ and $3.75 \times 10^{6}$ barrels per day of crude oil were combusted (Robinson 1992). The resulting fires produced several plumes of black and white smoke that coalesced to form a composite "super" plume. Because these fires were uncontrolled, significant quantities of organic materials were dispersed into the atmosphere and drifted throughout the Middle East. The organic particulants associated with the plume of the oil well fires had a potential to be rich in polynuclear aromatic hydrocarbon (PAH) compounds. Based on the extreme mutagenic and carcinogenic activities of PAHs found in laboratory testing, a serious health threat to the population of that region potentially existed. Furthermore, the Kuwait oil fire plumes represented a unique opportunity to study the atmospheric chemistry associated with PAHs in the plume. If samples were collected near the plume source and from the plume many kilometers downwind from the source, comparisons could be made to better understand atmospheric reactions associated with particle-bound and gas-phase PAHs. To help answer health-related concerns and to better understand the fate and transport of PAHs in an atmospheric environment, a sampling and analysis program was developed. The results of this sampling and analysis program are discussed in the following sections. 


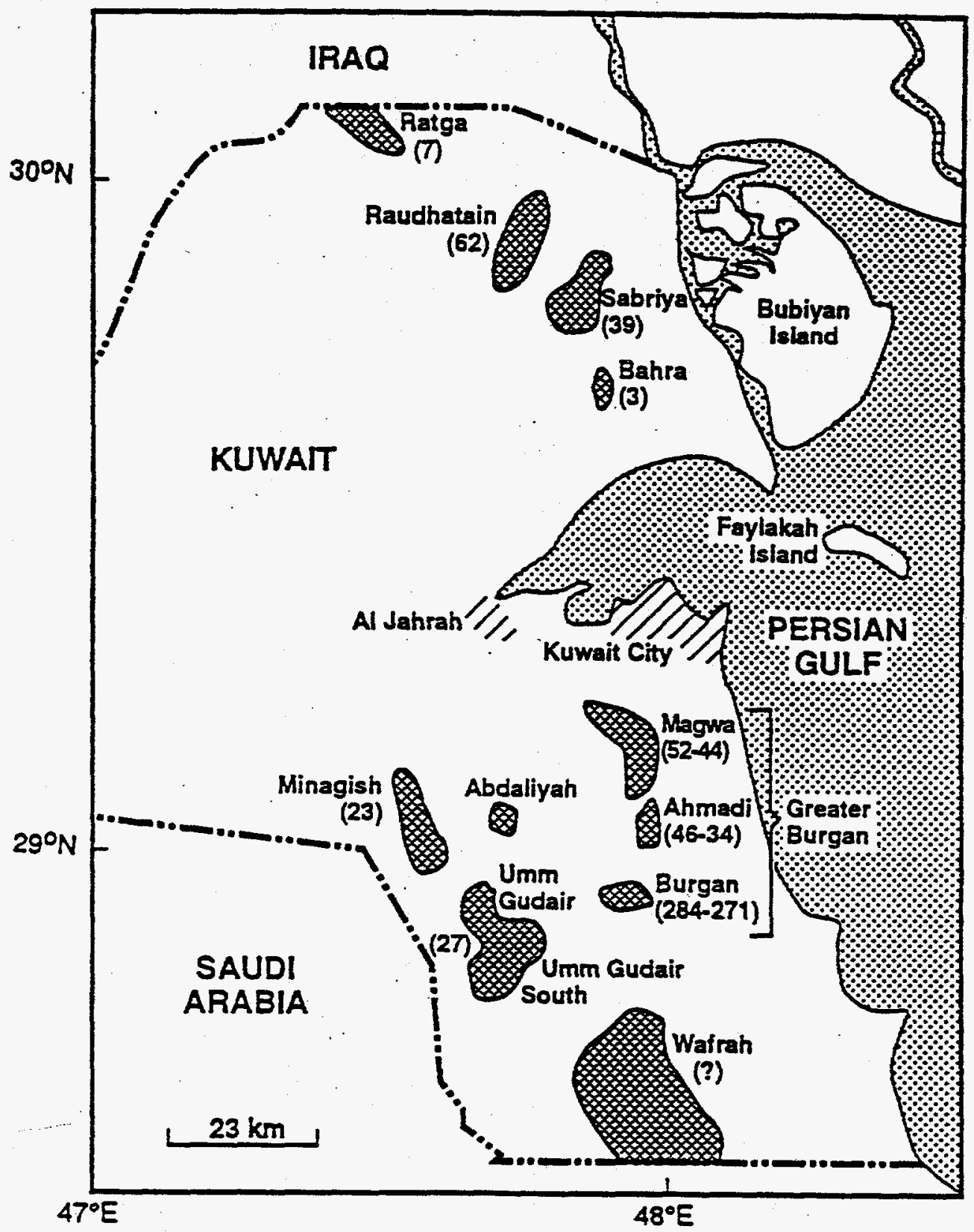

Figure 1. Map of Kuwait Showing Locations of Major Oil Fields and Numbers of Well Fires, March 1991 


\subsection{Experimental}

\subsection{Sample Collection}

Near-field sampling was conducted by the U.S. Environmental Protection Agency (EPA) using a helicopter as the sampling platform. Sampling was conducted during late July through the middle of August 1991. Sampling occurred from the plume sources to a maximum distance of $50 \mathrm{~km}$ downwind. Filter and/or Tenax trap samples were collected using a Versatile Air Pollutión Sampler (VAPS) sampling system (Figure 2). The sampler was equipped with 47-mm glass fiber filters with a 1.5-in. diameter stainless steel nipple packed with $3 \mathrm{~g}$ of Tenax gas chromatography (GC) (Olsen et al. 1983). Pacific Northwest Laboratory (PNL) provided several of the Tenax traps used for EPA's near-field sampling effort. Using the sampling arrangement discussed above, concentrations of particulate associated and gas-phase PAH compounds could be measured. EPA split portions of the glass fiber filters for confirmatory analysis with PNL and the Ford Motor Company (FMC). Table 1 identifies the samples EPA sent to PNL/FMC for analysis of critical collection parameters. Following collection, the filters and Tenax traps were stored at air-conditioned room temperatures in Kuwait, then hand-carried by EPA staff to Research Triangle Park in North Carolina. The samples were express mailed to PNL where they were stored at approximately $4^{\circ} \mathrm{C}$ until being shipped to FMC. Samples were stored at $-20^{\circ} \mathrm{C}$ at $\mathrm{FMC}$ until they were analyzed.

Far-field sampling (from 112 to $232 \mathrm{~km}$ downwind of Kuwait) was conducted using PNL's Gulfstream-1 aircraft (Figure 3). The flight number in Table 2 identifies the flight path during sample collection in Figure 3. A detailed description of the aircraft has been reported previously (Busness et al. 1992). Ambient air samples were directed to measurement systems in the cabin by externally mounted probes at the right forward side of the aircraft. Two 1-in. probes provided sample input to the integrated filter collection systems; each probe was monitored by flowmeters connected to the aircraft data acquisition system. All sample lines and manifolds were either Teflon or Teflon-lined to minimize contamination or chemical transformation of ambient samples. Air-jet vacuum ejectors installed on each engine, operating on high-pressure air from the engine compressors, created a vacuum for pumping samples through the filter-collection system. Manually-operated valves ahead of and behind each filter holder were used to control the flow through each filter pack. A specially designed filter pack for PAH sampling was developed that could easily be installed and removed from the filter-collection system (Figure 4). The filter pack consisted of an anodized aluminum head for mounting a 1.9-in.-dia. glass fiber filter (Whatman GF/F glass fiber filter) fired at $400^{\circ} \mathrm{C}$ for $4 \mathrm{hr}$, followed by a stainless steel honeycomb mesh for the filter support. The Tenax trap portion of the filter pack, constructed of stainless steel, slipped inside the aluminum head behind the glass fiber filter and was secured in place with allen screws. Each trap was packed with glass wool, followed by $4.5 \mathrm{~g}$ of Tenax prewashed in methanol and fired at $325^{\circ} \mathrm{C}$ under a helium purge, followed by another layer of glass wool. Segmentation of the chamber within the trap consisted of varying mesh sizes of stainless steel screen held in place with snap rings (Figure 4). A spacer was mounted to the rear of the Tenax trap to accommodate installation directly into the filter-collection system without modifications. 


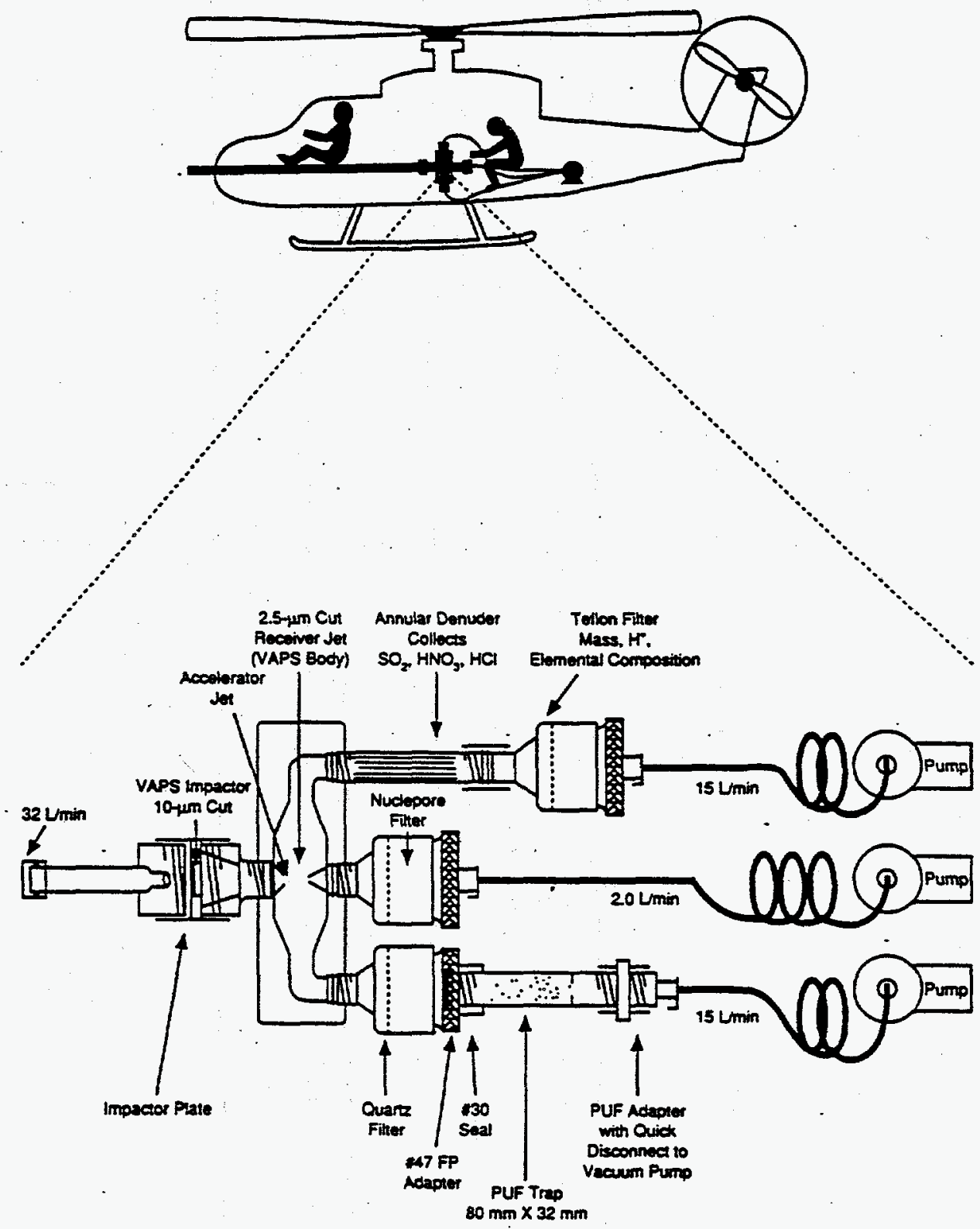

Figure 2. Schematic Diagram of the Helicopter Sampling Configuration and the VAPS Sampler System used for Near-Field Airborne Sampling 
Table 1. Sample and Sampling Parameters for EPA Helicopter Near-Field Sampling

\begin{tabular}{|c|c|c|c|c|}
\hline Sample ID & Sample Type & Date Collected & $\begin{array}{l}\text { Total Vol } \\
\text { Air }\left(\mathbf{m}^{3}\right)\end{array}$ & Comments \\
\hline Kuwait 102-SO-1 & Standard ${ }^{(\mathbf{a})}$ & $\mathrm{NA}$ & - & \\
\hline Kuwait 102-UD-1 & Standard(a) & NA & - & . \\
\hline KA 7-31-3-Q & Filter & 31-JUL-91 & 0.700 & \\
\hline HF 7-31-91 & Tenax & 31-JUL-91 & 0.690 & \\
\hline HF 8-2-91 & Tenax & 02-AUG-91 & - & \\
\hline $\mathrm{KA} 8-2-1-\mathrm{Q} 2$ & Filter & 02-AUG-91 & 0.050 & \\
\hline KA 8-2-1-Q1 & Filter & 02-AUG-91 & 0.050 & \\
\hline $\mathrm{KA} 8-3-1-\mathrm{Q} 2$ & Filter & 03-AUG-91 & 0.090 & \\
\hline $\mathrm{KA} 8-3-1-\mathrm{Q} 1$ & Filter & 03-AUG-91 & 0.090 & \\
\hline HF 8-3-91 & Tenax & 03-AUG-91 & - & no plume \\
\hline HF 8-5-91 & Tenax & 05-AUG-91 & 0.200 & \\
\hline KA 8-5-Q1 & Filter & 05-AUG-91 & 0.150 & \\
\hline $\mathrm{KA} \mathrm{8-5-Q2}$ & Filter & 05-AUG-91 & 0.150 & \\
\hline $\mathrm{KA} 8-6-\mathrm{Q} 1$ & Filter & 06-AUG-91 & 0.800 & . \\
\hline KA 8-6 & Tenax & 06-AUG-91 & - & 50-min super plumè \\
\hline $\mathrm{KA}-8-7$ & Tenax & 07-AUG-91 & - & white plume \\
\hline KA 8-7-1-Q & Filter & 07-AUG-91 & 0.090 & \\
\hline
\end{tabular}




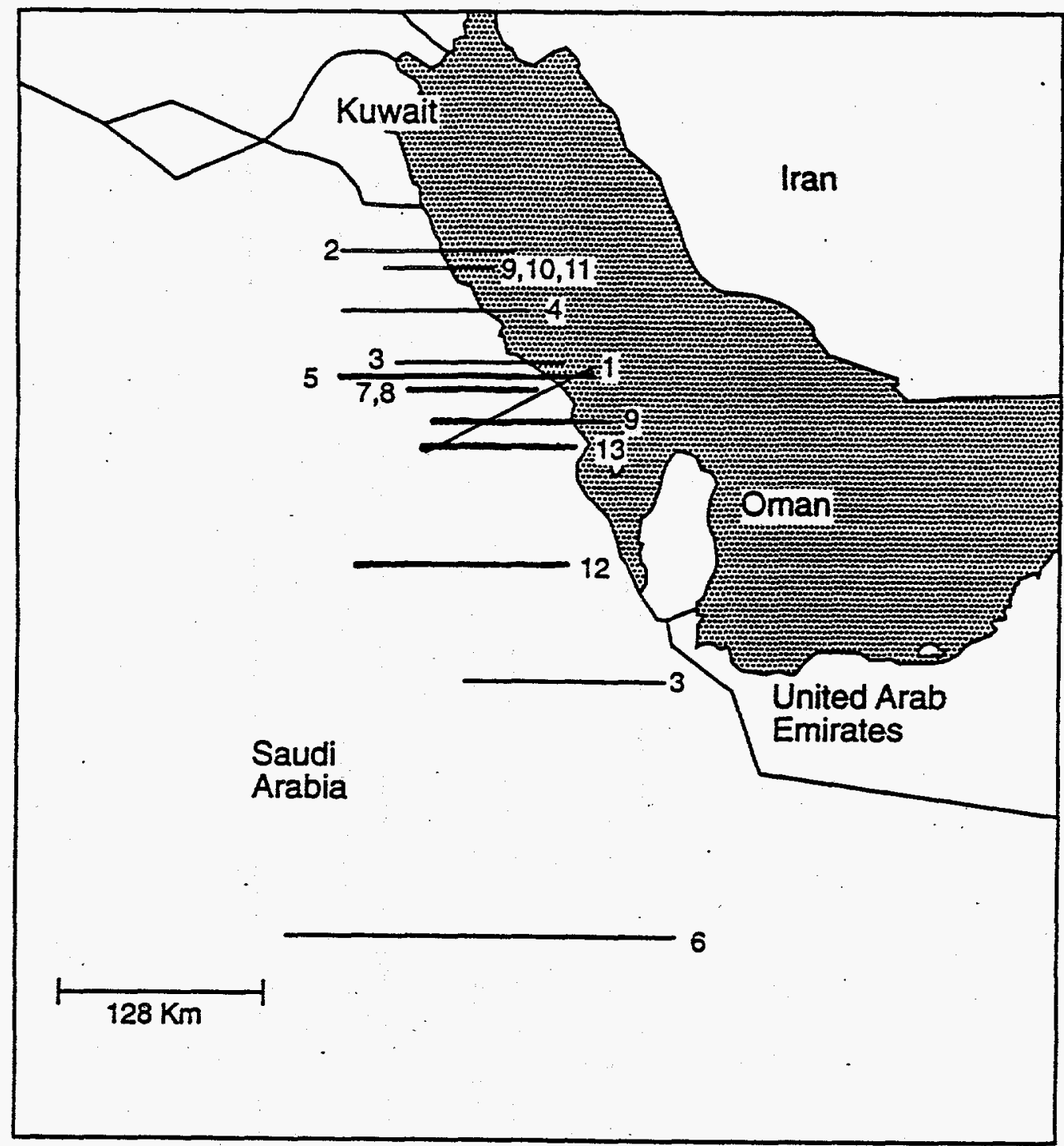

S9409063.2

Figure 3. Locations of Far-Field Sampling (112 to $232 \mathrm{~km}$ downwind of Kuwait) Using PNL's Gulfstream-1 Aircraft. Bold lines indicate PAH sampling flight paths.

Table 2 lists the samples and collection parameters used during aircraft sampling. A total of seven samples were collected from August 7 to August 17, 1991. Samples collected were stored at room temperature after collection. Unfortunately, after completion of the field sampling with the G-1 aircraft, the samples may have been exposed to extreme temperature in shipping containers in Bahrain while awaiting shipment back to PNL. Exposure to extreme temperatures may have resulted in volatilization losses of PAH compounds from the filters. However, the Tenax samples should have been unaffected because they have a strong affinity for PAH compounds. Upon arrival at PNL, the samples were stored at $4^{\circ} \mathrm{C}$ until they were analyzed. 
Table 2. Sample and Sampling Parameters for G-1 Aircraft Far-Field Study

\begin{tabular}{|c|c|c|c|c|c|c|c|}
\hline $\begin{array}{c}\text { Sample } \\
\text { Number }^{(a)}\end{array}$ & Sample ID & $\begin{array}{l}\text { Sample } \\
\text { Typo }\end{array}$ & $\begin{array}{c}\text { Dato } \\
\text { Collected }\end{array}$ & $\begin{array}{l}\text { Flight } \\
\text { Number }\end{array}$ & $\begin{array}{c}\text { Samplo Vol. Air } \\
\left(\mathrm{m}^{3}\right)\end{array}$ & $\begin{array}{l}\text { Distance }(\mathrm{km}) \\
\text { from Kuwait }\end{array}$ & Comments \\
\hline 1 & Lab Filter Blk & Filter & NA & - & - & - & \\
\hline 2 & Kuwait-47-SO-2 & Standard(b) & NA & - & - & - & \\
\hline 3 & Kuwait-47-UD-2 & Standand (b) $^{-}$ & NA & - & - & - & \\
\hline- & PNL-1 & Filter & 07-AUG-91 & 5 & 0.41 & 112 & $\mathrm{FMC}^{(\mathrm{c})}$ \\
\hline 4 & PNL-2 & Filter & 07-AUG-91 & 5 & 0.67 & 112 & \\
\hline 5 & $\mathrm{COB}$ & Pilter & 07-AUG-91 & 5 & - & - & System Blk \\
\hline 6 & PNL-2 & Filter & 11-AUG-91 & 7 & 0.68 & 120 & \\
\hline 7 & PNL-1 & Filter & 11-AUG-91 & 7 & 0.36 & 120 & \\
\hline 8 & PNL-1 & Filter , & 13-AUG-91 & 9 & 1.49 & 136 & \\
\hline 9 & PNL-1 & Filter & 16-AUG-91 & 12 & $@ 1.19$ & 232 & \\
\hline 10 & PNL-1 & Filter & 17-AUG-91 & 13 & 1.80 & 152 & \\
\hline 11 & Lab Tenax Blk & Tenax & NA & - & - & - & \\
\hline- & PNL-1 & Tenax & 07-AUG-91 & 5 & 0.41 & 112 & NA \\
\hline 13 & PNL-2 & Tenax & 07-AUG-91 & 5 & 0.67 & 112 & \\
\hline 12 & $\mathrm{COB}$ & Tenax & 07-AUG-91 & 5 & - & - & System Blk \\
\hline 14 & PNL-1 & Tenax & 11-AUG-91 & 7 & 0.68 & 120 & \\
\hline 15 & PNL-2 & Tenax & 11-AUG-91 & 7 & 0.36 & 120 & \\
\hline 16 & PNL-1 & Tenax & 13-AUG-94 & 9 & 1.49 & 136 & \\
\hline 17 & PNL-1 & Tenax & 16-AUG-91 & 12 & 01.19 & 232 & \\
\hline 18 & PNL-1 & Tenax & 17-AUG-91 & 13 & 1.80 & 152 & \\
\hline \multicolumn{8}{|c|}{$\begin{array}{l}\text { (a) PNL Samplo Identification Number (See Tables 4, 5, and 6). } \\
\text { (b) NIST SRM } 1580 \text { (Shalo Oil) or NIST SRM } 1649 \text { (PAHs in Urban Dust) Standards deposited on filter. } \\
\text { (c) Analyzed by Ford Motor Company. }\end{array}$} \\
\hline
\end{tabular}



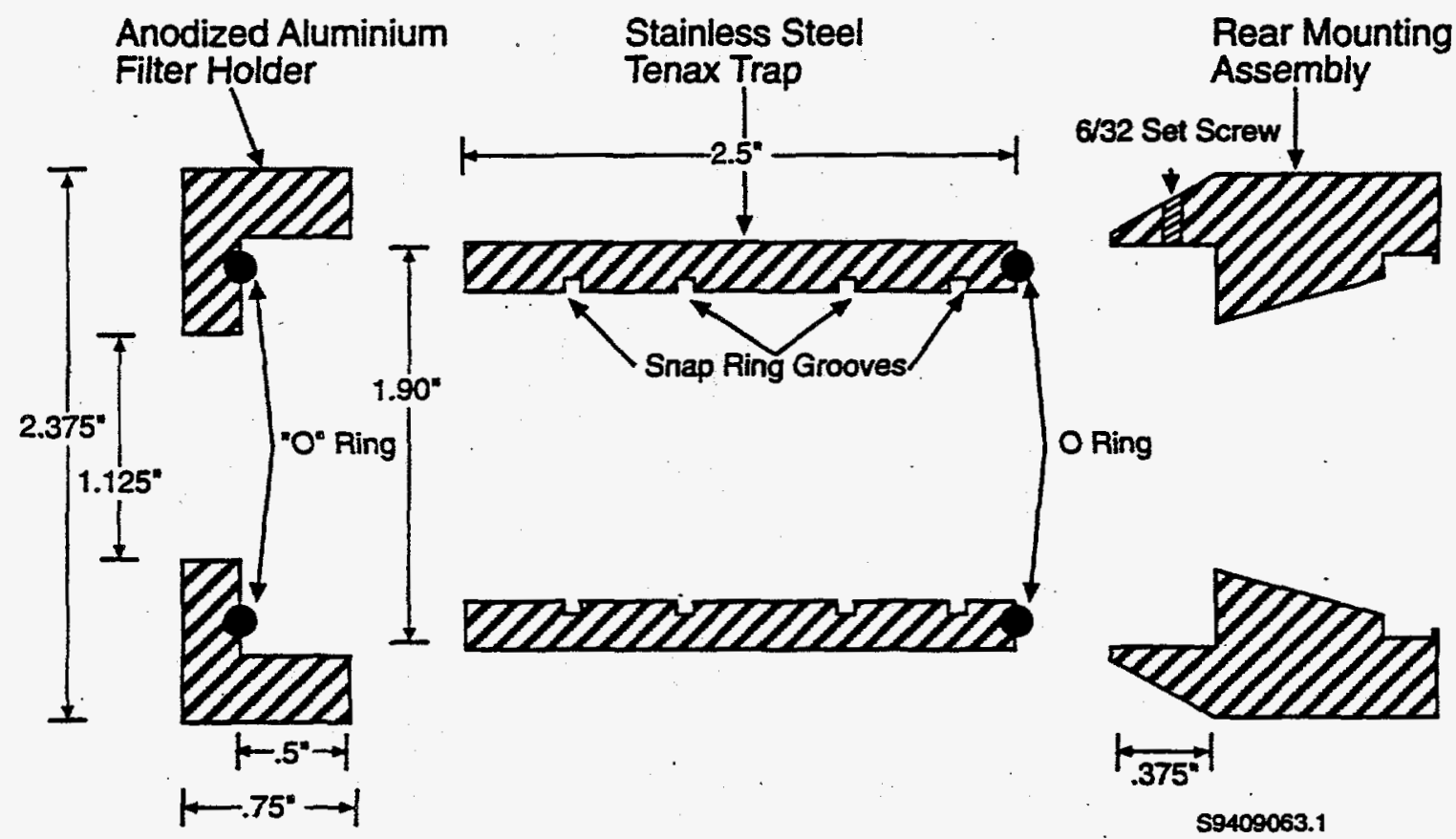

Figure 4. Diagram of a Specially Designed Filter Pack for PAH Sampling Developed to be Easily Installed and Removed from the Filter-Collection System

During trip preparations, additional filter and Tenax traps were prepared and refrigerated at $4^{\circ} \mathrm{C}$ in the laboratory. These traps and filters are identified in Tables 1 and 2 as laboratory filter blanks and traps. In addition, blank filters were spiked with known quantities of either National Institute of Standards and Technology (NIST) Standard Reference Material (SRM) 1580 (Shale Oil) or SRM 1649 (PAHs on Urban Dust). These standards contained know concentrations of PAH compounds as verified by NIST. Two filters spiked with the respective SRM materials accompanied each set of filters were sent to EPA for the near-field sampling and with the U.S. Department of Energy team conducting the far-field sampling. Each set of spike filter samples accompanied the samples sent to the respective laboratories for analysis. 


\subsection{Sample Analysis}

Extraction and analysis of the EPA-collected near-field samples were conducted at the FMC by Dr. James Ball. All glassware used in the extraction of filters was cleaned with chromic acid solution, rinsed with reverse osmosis water, rinsed with methylene chloride, and dried at $150^{\circ} \mathrm{C}$ overnight. Soxhlet apparatus was purged by refluxing overnight with methylene chloride. All extractions were carried out in subdued lighting under a positive pressure of dry nitrogen gas. Soxhlet extraction was carried out for about 16 hours with 3 to 4 cycles/hr. Each Soxhlet apparatus was heated using an oil bath to minimize local super heating. Local super heating at the glass-heating mantle interface can cause polymerization of reactive compounds. The temperature of the oil bath was maintained between 70 to $80^{\circ} \mathrm{C}$. The methylene chloride extracts were rotoevaporated to a small volume and transferred to a tared conical vial. The extract was concentrated to between 100 to $400 \mu \mathrm{L}$ under a stream of dry nitrogen gas. The two filters spiked with NIST Urban Dust and Shale Oil were concentrated to only 850 and $1750 \mu \mathrm{L}$, respectively, because these extracts contained considerably more extractable materials based on their intense yellow-brown color. The volumes were measured by using the weight of the extract and the density of methylene chloride at room temperature $\left(1.322 \mathrm{~g} / \mathrm{cc}\right.$ at $\left.23^{\circ} \mathrm{C}\right)$. Methylene chloride extracts of the individual filters were analyzed within 24 hours of being extracted.

Sixteen PAH compounds were analyzed in the near-field samples. The identity, selected mass ions used for quantification, and the detection limits of each PAH are shown in Table 3. Certified reference solutions containing these 16 PAHs were purchased from Ultra Scientific (North Kingstown, RI) and were diluted with methylene chloride in volumetric glassware. A standard curve was generated that ranged from 0.02 to $7.0 \mathrm{ng} / \mu \mathrm{L}$ depending on the specific PAH (see Table 3).

GC was carried out on a Hewlett-Packard 5890 GC interfaced with a Hewlett-Packard 5971A Mass Selective Detector: Two 30-m RTX-200 $(0.25 \mathrm{~mm}$ id, $0.25 \mu \mathrm{m}$ film thickness crossbonded trifluoropropyl methyl polymer) columns were used to separate the PAHs. The first column was used to analyze the filters from individual plumes and the reference filters, while the second column was used to analyze the filters from the composite plume downwind from the oil fires (Table 1). The first column was discarded after injection of the extracts from the very "dirty" filters coated with NIST Urban Dust (SRM 1649) and Shale Oil (SRM 1580). The following temperature program was used for the separation of the PAHs: $40-110^{\circ} \mathrm{C}$ at $15^{\circ} \mathrm{C} / \mathrm{min}$, hold at $110^{\circ} \mathrm{C}$ for one minute; $110^{\circ} \mathrm{C}$ to $300^{\circ} \mathrm{C}$ at $3.5^{\circ} \mathrm{C} / \mathrm{min}$. The injection port was $280^{\circ} \mathrm{C}$; the mass detector was at $275^{\circ} \mathrm{C}$. All injections were carried out using $1.0 \mu \mathrm{L}$ sample volumes, $0.5 \mu \mathrm{L}$ air, and $0.5 \mu \mathrm{L}$ methylene chloride in the splitless injection mode. The mass selective detector was set to analyze specific ions of the individual PAHs based on the retention times of standard PAHs.

Far-field filter and Tenax samples were extracted and analyzed by PNL. All glassware used in the extraction of filters was cleaned with chromic acid solution, rinsed with Milli-Q water, rinsed with methylene chloride, and dried at $150^{\circ} \mathrm{C}$ overnight. Soxhlet apparatus was purged by refluxing with methylene chloride or methanol, depending on the media to be used for extraction. Methylene chloride $(180 \mathrm{~mL})$ was used to extract the filter samples, and methanol $(150 \mathrm{~mL})$ was used to extract the Tenax traps. Soxhlet extraction was carried out for about 14-16 hours. Each Soxhlet apparatus was heated using a heating mantle assembly. The methylene chloride and methanol extracts were rotoevaporated to a small volume and transferred to a tared pear-shaped vial for further concentration. The extracts were. 
Table 3. Polycyclic Aromatic Hydrocarbons Analyzed by Selected Ion Gas Chromatography/Mass Spectrometer (GC/MS)

\begin{tabular}{|c|c|c|c|}
\hline $\begin{array}{c}\text { Polycyclic Aromatic } \\
\text { Hydrocarbon in Order of Elution }\end{array}$ & $\begin{array}{l}\text { Retention Time } \\
\text { (min) }\end{array}$ & $\begin{array}{c}\text { Selected in Mass Ions Used in } \\
\text { Analysis }(\mathrm{m} / \mathrm{e})\end{array}$ & $\begin{array}{l}\text { Detection Limit of PAH } \\
\text { (ng) }\end{array}$ \\
\hline Napthalene & 8.62 & $128 ; 129$ & 0.02 \\
\hline Acenapthene & 15.39 & $151 ; 152 ; 153 ; 154$ & 0.02 \\
\hline Acenapthylene & 15.74 & $151 ; 152 ; 153 ; 154$ & 0.02 \\
\hline Fluorene & 18.71 & $165 ; 166$ & 0.02 \\
\hline Phenanthrene & 25.34 & $178 ; 179$ & 0.02 \\
\hline Antracene & 25.62 & $178 ; 179$ & 0.02 \\
\hline Fluoranthene & 33.67 & $101 ; 102$ & 0.02 \\
\hline Pyrene & 34.79 & $101 ; 102$ & 0.02 \\
\hline Benzo[a]anthracene & 43.07 & $228 ; 229$ & 0.1 \\
\hline Chrysene & 43.17 & $228 ; 229$ & 0.1 \\
\hline Benzo[b]fluoranthene & 50.25 & $252 ; 253$ & 0.1 \\
\hline Benzo[k]fluoranthene & 50.40 & $252 ; 253$ & 0.1 \\
\hline Benzo[a]pyrene & 51.79 & $252 ; 253$ & 0.1 \\
\hline Indeno[1,2,3-cd]pyrene & 57.99 & $138 ; 139 ; 276 ; 278$ & 1.0 \\
\hline Dibenzo[ah]anthracene & 58.12 & $138 ; 139 ; 276 ; 278$ & 1.0 \\
\hline Benzo[ghi]perylene & 59.12 & $138 ; 276$ & 1.0 \\
\hline
\end{tabular}


concentrated to approximately $1 \mathrm{~mL}$ and transferred to reaction vials and adjusted to a volume of $1 \mathrm{~mL}$. Extracted samples were refrigerated at $4^{\circ} \mathrm{C}$ until analysis.

All samples, except sample 2, were blown down to near dryness $(-50 \mu \mathrm{L})$ using a stream of pure nitrogen. Samples 1 and 4 through 18 were diluted with $300 \mu \mathrm{L}$ HPLC-grade methylene chloride containing 2-chloro-anthracene as an internal standard. This volume was chosen as it is about the minimum volume that can be used with the autosampler. Sample 2 was diluted to $25 \mathrm{~mL}$ using HPLCgrade methylene chloride containing the internal standard. Sample 3 was diluted with $500 \mu L$ HPLCgrade methylene chloride containing the internal standard. The internal standard was at a final concentration of $50 \mathrm{ng} / \mu \mathrm{L}$. After dilution, the samples were transferred and sealed into autosampler vials for analysis.

Calibration standards were prepared at $0.625,2.50,10$, and $40 \mathrm{ng} / \mu \mathrm{L}$ concentrations by serial dilution of SV Calibration Mixture \#5 (Restek Corporation, Bellefonte, PA) containing $2000 \mathrm{ng} / \mu \mathrm{L}$ each of the following PAH: naphthalene, acenaphthylene, acenapthene, fluorene, phenanthrene, anthracene, fluoranthene, pyrene, benz[a]anthracene, chrysene, benzo[b]fluoranthene, benzo[a]fluoranthene, benzo[a]pyrene, indeno[1,2,3-cd]pyrene, dibenz[a,h]anthracene, and benzo[ghi]perylene. HPLC-grade methylene chloride containing the internal standard was used as diluent.

All samples were analyzed using a Hewlett-Packard 5880 gas chromatograph equipped with a $15 \mathrm{M}$ $\mathrm{x} 0.25 \mathrm{~mm}$ inside dia. fused silica capillary column coated with $0.25 \mu \mathrm{m}$ DB-5 (J \& W Scientific, Folsom, CA). The oven was temperature programmed from 50 to $275^{\circ} \mathrm{C}$ at $4^{\circ} \mathrm{C} /$ min with a 2 -min hold at the initial temperature and a 5-min hold at the final temperature. The injection port and flame ionization detector (FID) were operated at $275^{\circ} \mathrm{C}$ and $300^{\circ} \mathrm{C}$, respectively. Helium was used as the carrier gas at an approximately $50 \mathrm{~cm} / \mathrm{s}$ flow rate. The samples were analyzed using an autosampler set to deliver approximately $1 \mu \mathrm{L}$ /injection in the following order: calibration standards, filter samples, calibration standards, Tenax trap samples, calibration standards, urban dust sample, and shale oil sample. Blanks containing the internal standard were analyzed before the analysis of sample sets to ensure that there was no carryover of PAH compounds from the calibration standards. The urban dust and shale oil samples, known to contain large amounts of organic compounds, were analyzed last so that they did not contaminate the system while the lower level filter and trap samples were being analyzed. A sample of a coal tar test mixture that had been previously characterized by GC/MS was also analyzed to give the retention times of additional PAH compounds for which no standards were made.

The average response factors of the individual PAH compounds in the calibration standards were calculated based on both area and height response. The response factors from the calibration standard, with the nearest concentration to that found in the actual samples, were used for calculations.

Response factors of the closest eluting standard compounds were used for the PAH compounds for which there were no standards. Quantitative values were calculated using both area and height response, after which the results were averaged. Total ng (or $\mu \mathrm{g}$ for sample 2) amounts are reported. Minimum detectable amounts were about $20 \mathrm{ng}$ for samples 1 and 4 through 18 , about $40 \mathrm{ng}$ for sample 3, and about $1.8 \mu \mathrm{g}$ for sample 2 . All identifications are based on retention time only and may be representative of co-eluting species. 
Samples 6,11 , and 17 were also analyzed by GC/MS using a Varian Satum Ion Trap mass spectrometer. The chromatographic conditions were as follows: $30 \mathrm{~m} \times 0.25 \mathrm{~mm}$ inside dia. fused silica capillary column coated with $0.25 \mu \mathrm{m}$ DB-5 (J \& W Scientific); 60 to $280^{\circ} \mathrm{C}$ at $7^{\circ} \mathrm{C} / \mathrm{min}$ with a 2-min initial time and a 10-min hold at the final temperature; $1 \mu \mathrm{L}$ injection. 


\subsection{Results}

With the exception of the two standard reference samples, none of the near-field filters showed any PAH compounds after correcting for the blank filter (Ball et al. 1993). Figure 5 shows a chromatogram of $1 \mathrm{ng}$ of each PAH compound in the standard mixture. Several of the PAH compounds eluted as incompletely resolved pairs. For example, the following PAH compounds were not completely resolved; benzo[a]anthracene and chrysene, benzo[a]fluoranthene and benzo[ah]anthracene. An example of one GC/MS chromatogram of the filter extract is shown in Figure 6. There are numerous GC peaks present in the extract of filters from the smoke plumes. However, very few of these peaks correspond to any of the PAH compounds in Table 3. In each filter extract, including the filter blank, naphthalene was present, and for some filter extracts there were small amounts of fluorene, phenanthrene, and anthracene. The extract of the blank filters also showed these PAH compounds at the same concentrations. The chromatogram of a methylene chloride extract of a clean filter (filter blank) is shown in Figure 7. If these smoke plume filter extracts are corrected for the presence of PAH compounds in the filter blank, then no detectable PAH compounds are found in any of the filter extracts. The PAH compounds found in the urban dust sample tend to be the higher molecular weight PAH compounds, whereas the PAH compounds found in the Shale Oil sample are mainly the lower molecular weight PAH compounds listed in Table 3. No attempt was made to quantify these PAH compounds because of the lack of PAH compounds in the plume filter samples. There was one possible complication in the extraction of the near-field filter samples. The concentrated methylene chloride extracts of the filters showed a white, gelatinous material that may have absorbed PAH compounds. If this occurred, the $\mathrm{PAH}$ concentrations measured could have been artificially low. This possibility was tested by resuspending a filter extract with methylene chloride spiked with approximately $1 \mathrm{ng} / \mu \mathrm{l}$ of PAH compounds in the standard mixture. To within experimental error, there was no apparent loss of PAH compounds to the gelatinous material.

The results of the GC analysis of the far-field filter samples are given in the Table 4. Sample identification is listed in Table 2. Few compounds were identified that had retention times that corresponded to the retention times of known PAH compounds. All of the compounds identified as PAH (by retention time) in the samples were very minor components in the chromatograms. In addition to those PAH compounds quantified in the table, there were some baseline peaks in the chromatograms that possibly could have been PAH, but they were below the minimum detectable limit of approximately $20 \mathrm{ng}$ in the sample. Other major components were present in all of these samples, but their retention times did not correspond to those of PAH compounds. A peak with a retention time that matched anthracene was found in all of the samples at about the same level. Because it was also present in the blank (sample 1), it is likely that this is a contaminant peak. Because all the compounds that were identified were basically baseline peaks, it is also highly likely that the compounds quantified are merely artifacts and not necessarily PAH compounds.

The results of the GC analysis of the far-field Tenax trap samples are given in the Table 5. Sample identification is listed in Table 2. More compounds that had retention times corresponding to PAH compounds were detected in the Tenax trap samples than in the filter samples. However, the quantitative results from the Tenax blank (sample 11) also reflected the increased concentration of compounds detected. Again, the compounds identified as PAH compounds by retention times were not the major 


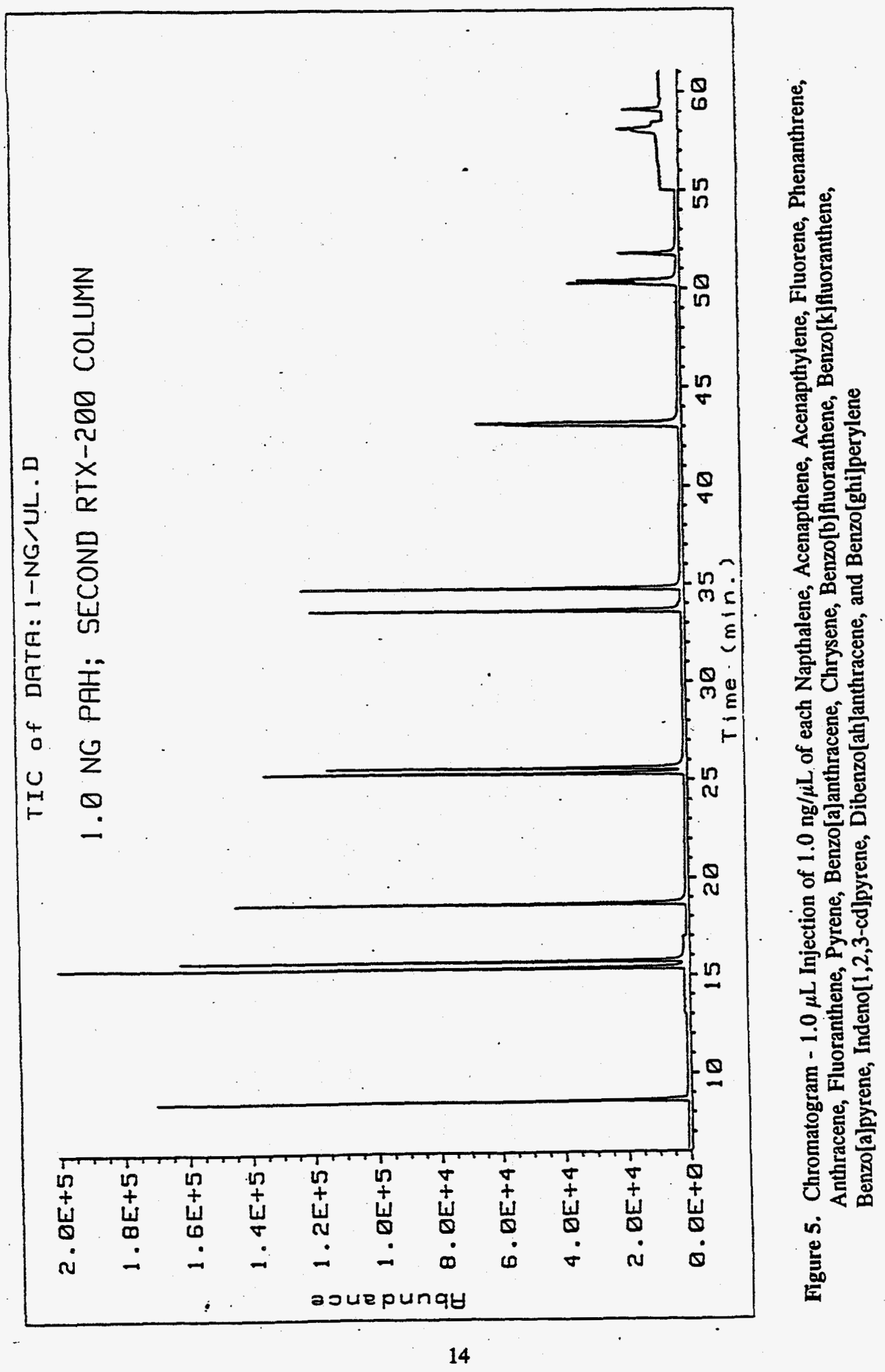




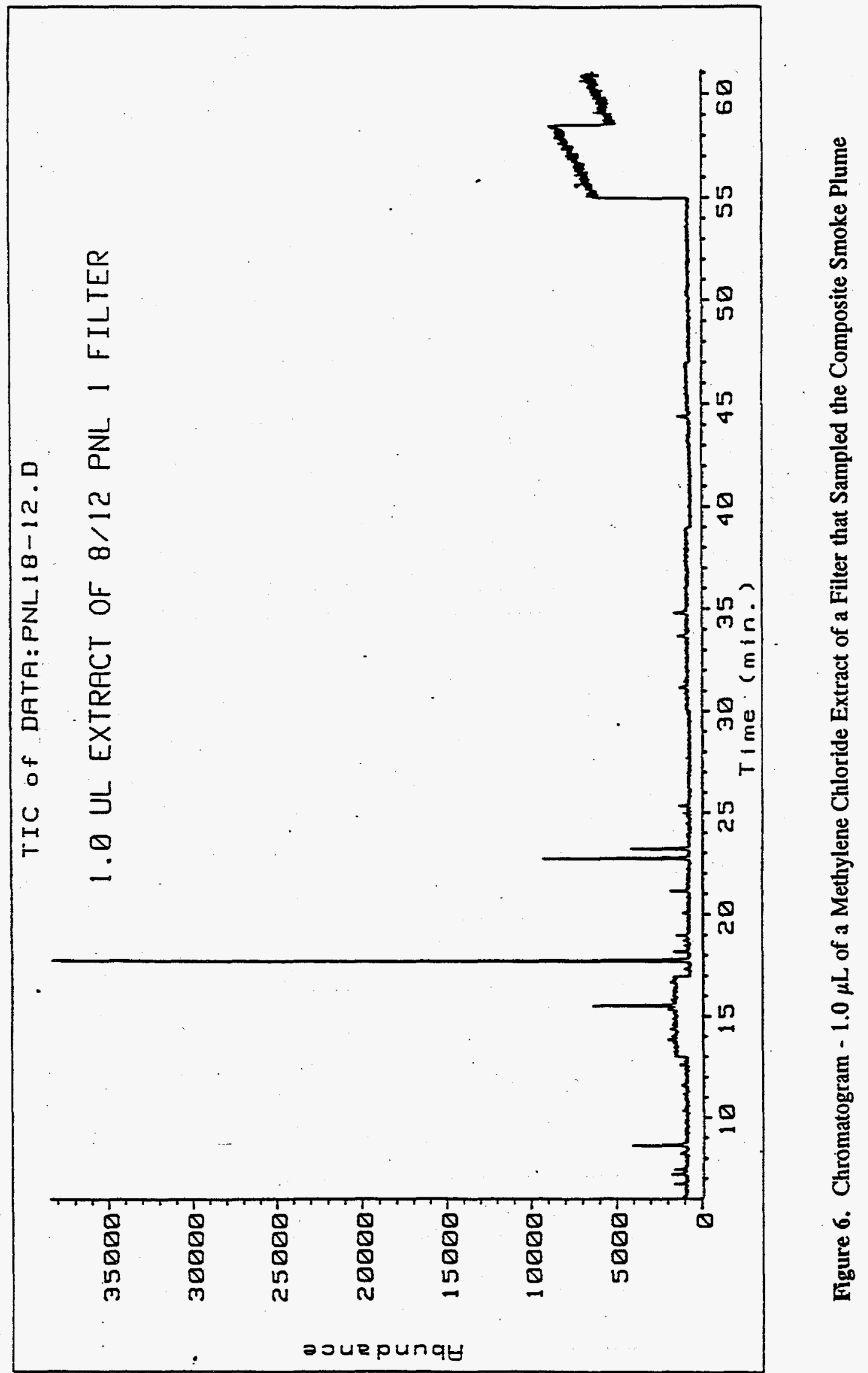




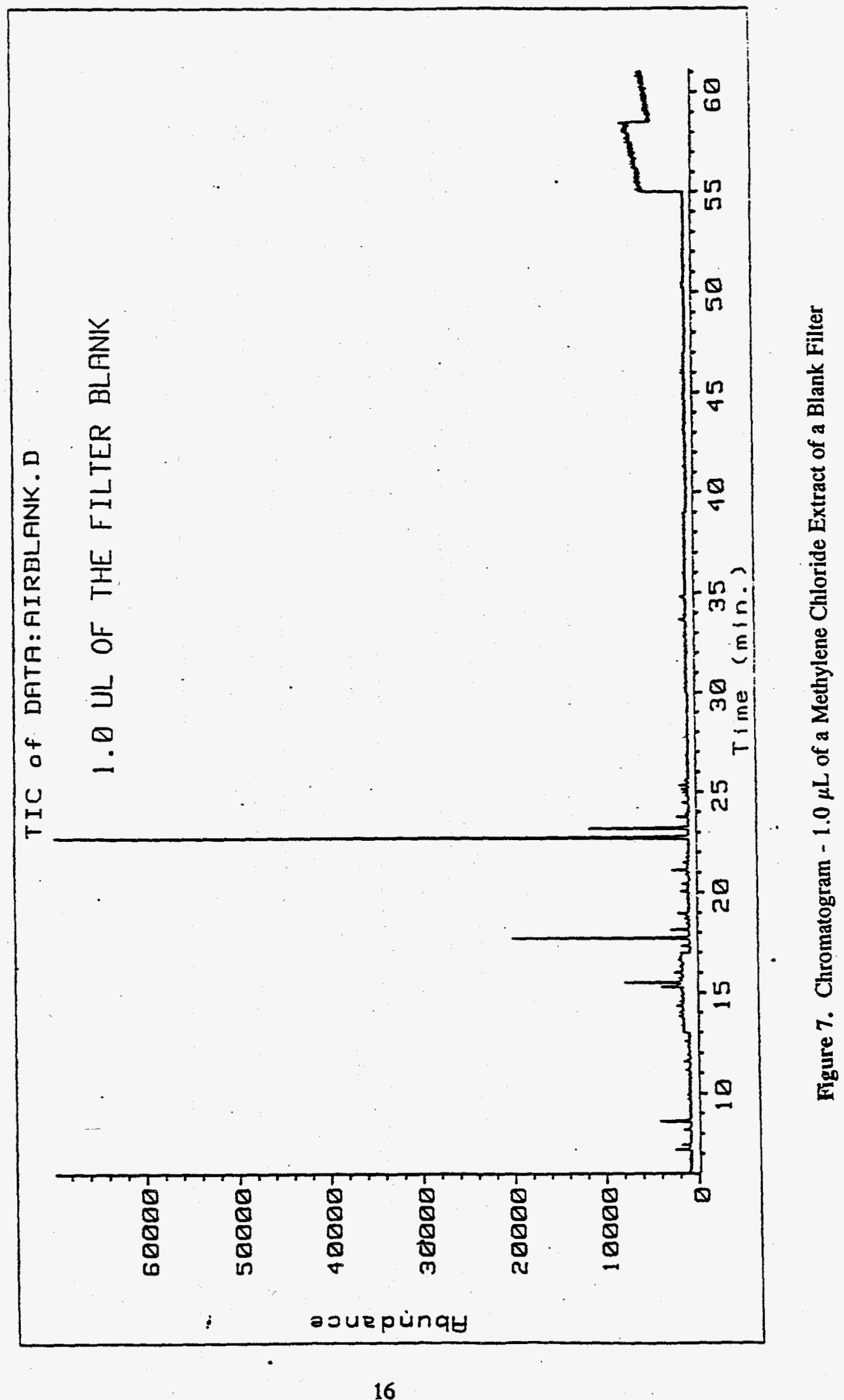


Table 4. Results from Far-Field Filter Samples (Total ng Amounts Detected) ${ }^{\text {(a) }}$

\begin{tabular}{|c|c|c|c|c|c|c|c|c|}
\hline Compound & Sample 1 & Sample 4 & Sample 5 & Sample 6 & Sample 7 & Sample 8 & Sample 9 & Sample 10 \\
\hline \multicolumn{9}{|l|}{ Napthalene } \\
\hline \multicolumn{9}{|l|}{ Acenapthylene } \\
\hline \multicolumn{9}{|l|}{ Acenaphthene } \\
\hline \multicolumn{9}{|l|}{ Fluorene } \\
\hline \multicolumn{9}{|l|}{ Phenanthrene } \\
\hline Anthraceno & 96 & 100 & 100 & 100 & 93 & 94 & 110 & 96 \\
\hline \multicolumn{9}{|l|}{ 3-Methylphenanthrene } \\
\hline 2-Methylphenanthrene & & & & 67 & & & & 28 \\
\hline \multicolumn{9}{|c|}{ 4H-Cyclopenta[def]phenanthrene } \\
\hline Fluoranthene & & & 41 & 14 & & & & \\
\hline \multicolumn{9}{|l|}{ Acephenanthrylene } \\
\hline Pyrene & & & & 20 & & & & \\
\hline \multicolumn{9}{|l|}{ Benzo[a]fluorene } \\
\hline \multicolumn{9}{|l|}{ Benzo[b]fluoreno } \\
\hline \multicolumn{9}{|l|}{ Benzo[a]anthraceno } \\
\hline \multicolumn{9}{|l|}{ Chrysene } \\
\hline \multicolumn{9}{|l|}{ Benzo[b]fluoranthene } \\
\hline \multicolumn{9}{|l|}{ Benzo[k] fluoranthene } \\
\hline \multicolumn{9}{|l|}{ Benzo[e]pyrene } \\
\hline \multicolumn{9}{|l|}{ Benzo[a]pyrene } \\
\hline \multicolumn{9}{|l|}{ Perylene } \\
\hline \multicolumn{9}{|l|}{ Indeno $[1,2,3-c d]$ pyrene } \\
\hline Dibenzo[a,h]anthracene & & & 55 & & & & & \\
\hline Benzo[ghi]perylene & & & & & & & & \\
\hline
\end{tabular}


Table 5. Results from Far-Field Tenax Traps (Total ng Amounts Detected) (a)

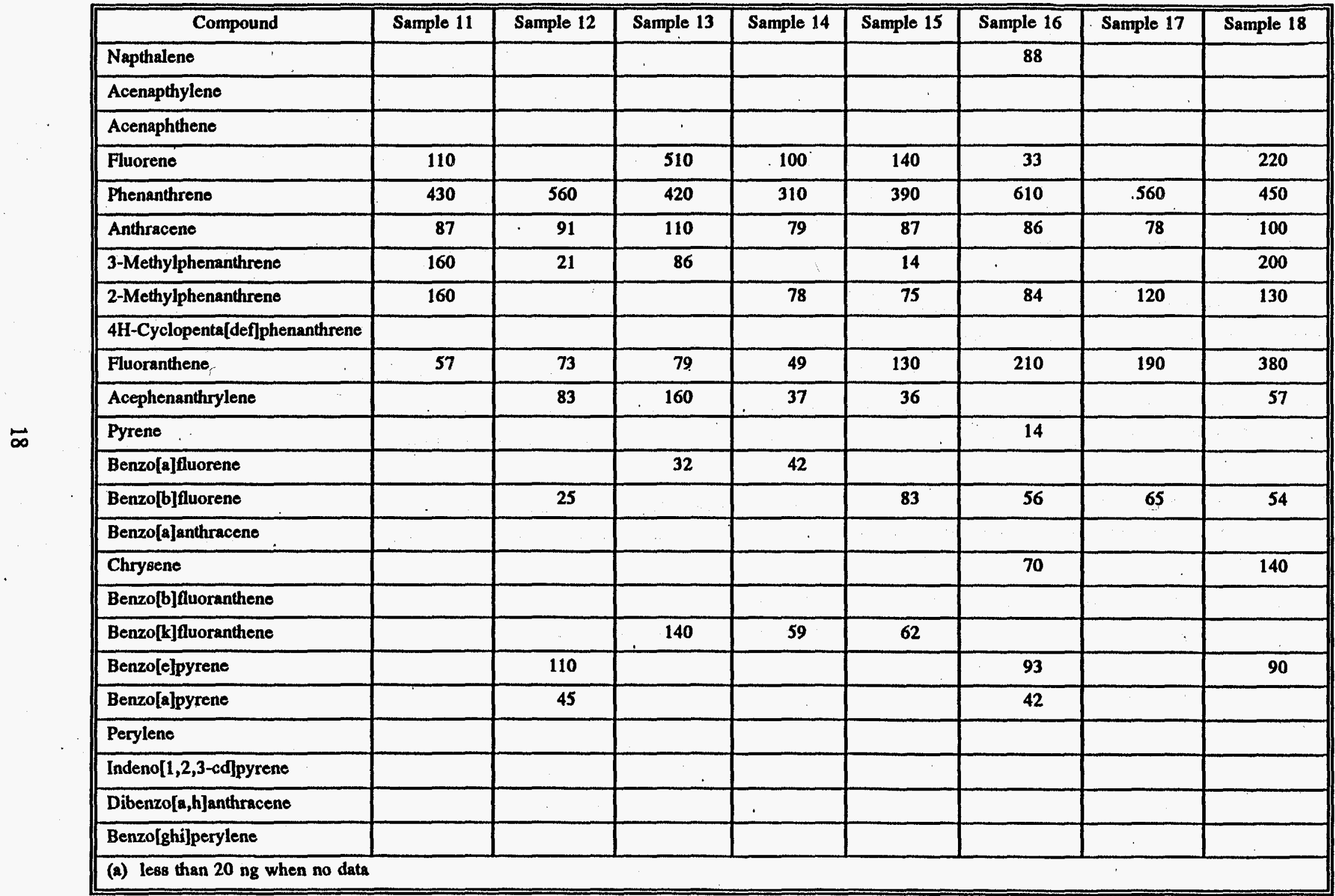


compounds in the chromatograms of these samples but were only minor components, many of which were again in the baseline of the chromatograms and may be merely artifact. Further analysis by GC/MS would elucidate the information gathered by GC.

The results of the GC analysis of the shale oil and urban dust samples are given in the Table 6 . The PAH amounts detected in the shale oil were about two to three orders or magnitude greater than those detected in the filter or Tenax samples. Because the shale oil was not fractionated into a clean PAH fraction, the quantitative values reported may also represent co-eluting species that are found in this highly complex organic mixture. Increased levels of PAH compounds were also detected in the urban dust samples compared to the filter and Tenax trap samples. There is also the possibility of coeluting species present in this complex mixture.

Some of the major components in the samples were phthalate contaminants. Other more minor components appeared to be high molecular weight aliphatic hydrocarbons. The majority of the components was not identified, mainly because they were present in both the samples and the blanks, and the library search of compounds gave matches that were not consistent with the chromatographic profile. An in-depth analysis for the identification of all compounds present in the chromatograms was not performed because the chromatographic profiles of the samples and their blanks were nearly identi$\mathrm{cal}$, indicating that any identifications performed were only representative of background contamination. The GC/MS analysis failed to detect PAH compounds from two to six rings in these samples. These GC/MS results indicate that the PAH quantified in the Tables 1 through 6 were either at levels below the detection limit of the GC/MS or that the organic compounds, with retention times corresponding to the PAH compounds, were merely co-eluting non-PAH compounds. 
Table 6. Results from Urban Dust and Shale Oil-Spiked Filter Samples (Total ng Amounts Detected)

\begin{tabular}{|c|c|c|}
\hline Compound & $\begin{array}{l}\text { Sample } 2 \\
(\mu g)^{(a)}\end{array}$ & $\begin{array}{l}\text { Sample } 3 \\
\text { (ng) }\end{array}$ \\
\hline Napthalene & 21 & \\
\hline Acenapthylene & 44 & 240 \\
\hline \multicolumn{3}{|l|}{ Acenaphthene } \\
\hline Fluorene & 18 & \\
\hline Phenanthrene & 22 & 130 \\
\hline Anthracene & 64 & 210 \\
\hline 3-Methylphenanthrene & 2.5 & \\
\hline 2-Methylphenanthrene & & 230 \\
\hline 4H-Cyclopenta[def]phenanthrene & 31 & 75 \\
\hline Fluoranthene & 32 & 220 \\
\hline \multicolumn{3}{|l|}{ Acephenanthrylene } \\
\hline Pyrene & 7.4 & 160 \\
\hline Benzo[a]fiuorene & 24 & \\
\hline \multicolumn{3}{|l|}{ Benzo[b]fluorene } \\
\hline Benzo[a]anthracene & 1.9 & 440 \\
\hline Chrysene & 6 & 770 \\
\hline Benzo[b]fluoranthene & 22 & 800 \\
\hline Benzo[k]fluoranthene & 8.3 & \\
\hline Benzo[e]pyrene & 28 & 410 \\
\hline Benzo[a]pyrene & 27 & 1200 \\
\hline Perylene & 7.7 & \\
\hline Indeno $[1,2,3-c d] p y r e n e$ & & 760 \\
\hline Dibenzo[a,h]anthracene & & 340 \\
\hline Benzo[ghi]perylene & & \\
\hline $\begin{array}{l}\text { (a) less than } 1.8 \mu \mathrm{g} \text { when no data } \\
\text { (b) less than } 40 \mathrm{ng} \text { when no data }\end{array}$ & & \\
\hline
\end{tabular}




\subsection{Conclusions}

There are three possible explanations for the lack of PAH compounds associated with particles from the Kuwait oil fires and air samples from within the plume of the oil fires. The first possibility is that the concentrations of PAH compounds associated with the particles and in the gas phase are very low in the plume, below the level of detection by GC-FID or selected ion GC/MS. The second possibility is that there was an insufficient quantity of particulate matter or air collected during sampling. Because of insufficient data on the mass of samples collected on the filter samples, there is no way to distinguish which one of the first two scenarios was more likely for the near-field samples. The same is true for the far-field samples, and the problem is compounded because the integrity of the filter samples is questionable because of possible exposure to elevated temperatures during shipment.

Reports of other researchers (Stevens et al. 1993) conducting similar sampling of the Kuwait oil fire plumes failed to identify significant concentrations of PAH compounds associated with the oil well fires. This conclusion is totally unexpected, given the vast quantities of crude oil burned and the many reports in the literature stating the production of PAH compounds is favored under no-ideal combustion conditions. A possible explanation for failure to find any PAH compounds may be related to the tendency of the black soot material in the plume to irreversibly bind the PAH compounds to active sites on its surface. 


\subsection{References}

Busness, K. M., A. A. Al-Sunaid, P. H. Daum, J. M. Hales, R. B. Hannigan, M. Mazurek, J. M. Thorp, S. D. Tomich, and M. J. Warren. 1992. Pacific Northwest Laboratory Gulfstream 1 Measurements of the Kuwait Oil-Fire Plume July - August 1991." . PNL-8436, Pacific Northwest Laboratory, Richland, Washington.

Olsen, K. B., D. R. Kalkwarf, and C. Veverka, Jr. 1983. "Analysis and Collection of PAHs in the Flue Gas of Energy Conversion Facilities." In Proceedings of the 8th International Symposium on Polynuclear Aromatic Hvdrocarbons, Columbus, Ohio, October 26-28.

Robinson, J. 1992. "Locations of the Burning Wells and the Rate at Which They Were Extinguished." Paper presented at the Second Meeting of Experts to assess the response to, and the Atmospheric Effects of, the Kuwait Oilfield Fires. World Meteorological Organization, May 25-29, 1992; Geneva, Switzerland.

Stevens, R., J. Pinto, Y. Mamane, J. Ondov, M. Abdulraheem, N. Al-Majed, M. Sadek, W. Cofer, W. Ellenson, and R. Kellogg. 1993. "Chemical and Physical Properties of Emissions from Kuwait Oil Fires." Wat. Sci. Tech., Vol. 27, No. 7-8, pp 223-233. 


\section{Distribution}

No. of

Copies

Offsite

2 DOE Office of Scientific and

Technical Information

M Abbott

Laboratory Management Division

U.S. Department of Energy

Office of Energy Research

Forrestal Building (ST-311)

1000 Independence Avenue, SW

Washington, D.C. 20585

T Vojnovich

Technical Program Manager

ER Laboratory Technology Transfer

Program

U.S. Department of Energy

Office of Energy Research

Forrestal Building (ST-311)

1000 Independence Avenue, SW

Washington, D.C. 20585

\section{A Zerega}

Laboratory Management Division

U.S. Department of Energy

Office of Energy Research

Forrestal Building (ST-311)

1000 Independence Avenue, SW

Washington, D.C. 20585
No. of

Copies
Dr. James Ball

Ford Motor Company

Scientific Research Laboratory

Mail Drop 3083

Dearborn MI 48121-2053

Dr. Robert Stevens

U.S. Environmental Protection

Agency

Atmospheric Research \& Exposure

Assessment Lab

Research Triangle Park, NC 27711

\section{Onsite}

DOE/Richland Operations Office

NL Hieb

K8-50

18 Pacific Northwest Laboratory

$\begin{array}{ll}\text { CM Berkowitz } & \text { K9-37 } \\ \text { KM Busness } & \text { K9-37 } \\ \text { M Clement } & \text { K1-17 } \\ \text { BJ Harrer (2) } & \text { K1-12 } \\ \text { KB Olsen (5) } & \text { K6-96 } \\ \text { C Veverka } & \text { K6-96 } \\ \text { CW Wright } & \text { P7-07 } \\ \text { Publishing Coordination } \\ \text { Technical Report Files (5) }\end{array}$

Distri. 1 